Dr. A. Landsborough Thomson pointed out that our ignorance of bird navigation is so great that we cannot afford to neglect any suggestions however far-fetched they may seem. He did not think that the suggestion that young birds migrating for the first time without their parents might merely have a tendency to go southwards towards the sun would carry us very far, since so much migration is not in the north-south line. He had no doubt at all that visual recognition plays a very large part in the orientation and migration of birds; but it does not, so far as we can see at present, give us a complete answer. Dr. Thomson agreed with previous criticisms of Yeagley's experiments, particularly because the birds were taken to the conjugate point and in some cases had been accustomed to that point before being taken to the release point. They should have been taken to the release point first.

Prof. V. C. Wynne-Edwards gave an account of his experiences with the release of herring gulls, and expressed agreement with the criticisms of Yeagley's work. He adhered to the view that in the end we shall find everything can be explained on a visual basis. He also suggested the possibility that the excellent time sense of birds might enable a bird to recognize a particular latitude by the time of sunrise.

Mr. James Fisher suggested that operating on a deliberate bias might be one of the methods by which birds can find their way in unknown country more efficiently than by theoretical spiral travelling. Thus if Lack and Lockley's famous shearwater released at Venice had operated on the principle of going along a right-handed coast it would eventually have reached the Bay of Biscay and thus presumably familiar territory.

Mr. B. W. Tucker agreed with the criticisms of Yeagley's experiments which had been put forward. But while much migration and homing can be explained in terms of visual responses, he felt that this cannot at present account for everything, and there are phenomena which are not completely explicable on the basis of any of the straightforward known senses. He pointed out that particular difficulties were raised by migration to oceanic islands and by the orientation behaviour of birds such as penguins.

Dr. M. H. Pirenne dealt with the subject of the sensitivity of birds' eyes and gave details of his experiments on owls and their response to infra-red rays. Discussing the work of Wojtusiak, Vanderplank and others, he pointed out various difficulties of interpretation and concluded that satisfactory evidence for infra-red vision is still lacking both in reptiles and birds. The fundamental difficulties raised by the infra-red radiation of the eye itself and associated tissues and by the infra-red absorptive power of the water in the eye were also discussed.

Mr. R. G. Newton suggested various possible methods by which the exact route taken by birds on release might be more easily traced.

${ }^{1}$ Ruppell, W., J. Orn. Lpz., 92, 106 (1944).

2 Griffin, D. R., Quart. Rev. Biol., 19, 15 (1944).

${ }^{3}$ Griffin, D. R., Bird Banding, 14, 7 (1943).

- Griffin, D. R., and Hock, R. J., Science, 107, 347 (1948).

${ }^{5}$ Yeagley, H. L., J. App. Physics, 18, 1035 (1947).

- Ising, G., Ark. Mat. Astron. och Fysik, 32 A, N.18.1 (1945).

${ }^{7}$ Thorpe, W. H., and Wilkinson, D. H., Nature, 158, 903 (1946).

${ }^{8}$ Wojtusiak, R. J., Proc. Linn. Soc., 160, Part 2 (in the press, 1948).

- Wojtusiak, R. J., Bull. Acad. Polon. Sci, et Lett. (Classe Sci. Math. et Nat.), Ser. B, Sci. Nat., 2, 43 (1947).

\section{MEDICAL RESEARCH DURING WAR-TIME}

$\mathrm{C}$

RITICS of science, whatever their motives, have not neglected to make capital out of the destructive uses to which scientific results have been put by man; and critics of planned research, moved no doubt by purely scientific reasons, have vigorously asserted that planning hampers and may min the creative abilities of scientific men. To both these groups of critics the Report of the Medical Research Council for the years 1939-45, entitled "Medical Research in War" (Cmd. 7335. London: H.M. Stationery Office, 1947. Pp. 1-455. 7s. 6d. net), is to be commended. For in it the former will find a long record of beneficent uses to which scientific results have actually been put; and the latter will learn from it that planning, provided that it is wisely done by broadminded men who understand, and them. selves experience, the mental processes and disciplines of scientific work, can produce both useful results and fundamental discoveries which advance the frontiers of knowledge. The proviso is a sine qua non; for planning that fails to recognize the basic individualism of scientific men and their kinship with artists imposes fatal limitations upon the research worker. The report is, for this reason, a tribute, not only to the men and women who have done the humane work that it records, but also to those who have, in their several ways, created and woven the themes treated, made the opportunities and provided the money and equipment without which the work could not have been accomplished.

The report, as its title implies, covers work done during the period of the Second World War. Military and industrial requirements, and also the health of the civil population therefore dominate its contents. The extent of the achievement recorded and the variety of the different, but often related, subjects investigated make it impossible, in a short review, to do much more than whet the appetite, so to speak, of potential readers and to invite them to read the report itself.

Apart from the information given about the composition and functions of the Medical Research Council and its committees, its arrangements for liaison with other men of science and scientific organisations in the United Kingdom, in other parts of the Commonwealth and in Allied countries, the names of its personnel, the publications of its research workers and the Council's own reports and $\mathbf{8}$ good deal of kindred information, there are fifteen sections which describe specific researches in considerable detail. These are summarized in a valuable "Introduction".

The subsequent sections deal with work on wounds and injuries; war diseases; therapeutics, including a useful account of the work on penicillin; war-time nutrition; personnel research done to increase the efficiency of the Fighting Services; health research in industry; special emergency services, such as blood transfusion, the emergency public health laboratory service in Britain and the supply of necessary immunological sera and antitoxins; the preparation and maintenance of biological standards of such substances as penicillin, vitamins $\mathrm{A}$ and $\mathrm{E}$, heparin and certain serological reagents, together with the maintenance of the national collection of type cultures of micro-organisms; and a great deal of other work done either at the National Institute 
for Medical Research or elsewhere on a variety of subjects, of which the control of cross-infection in hospitals, the birth-rate, population trends, air-borne infection, the remarkable work on scrub-typhus and research on burns and scalds and applied psychology are a few examples. The report, in fact, amounts to a guide to the major trends of medical research in Britain at the present day.

The three main objectives of all this work have been : (1) the maintenance of the health of the Armed Forces and the civilian population, with special regard for malnutrition and the prevention of infectious diseases; (2) the restoration of the wounded and sick to full health; and (3) the creation of conditions which will ensure the highest possible efficiency, safety and comfort of fighting personnel and industrial workers in time of war.

The effort to attain the first of these objectives was very successful. Epidemic infective disease has always been a military menace, but during the Second World War it was reduced to military insig. nificance. In civil life it was also checked, although the common cold, influenza and a variety of industrial hazards remain and are recognized as urgent problems which are now being energetically investigated. The value of the nutritional work done during the War is so well recognized that it needs no comment here.

The success of the attack on the second objective is probably not fully appreciated outside the medical profession. Powerfully aided by the discovery of the sulphonamide drugs and the effects of penicillin, and by remarkable advances in surgical treatment, the work done in this field saved the lives and returned to useful occupation many men and women who formerly would have either died or would have survived only in helplessness and misery.

The story of the attack on the third objective is in some respects the most interesting part of the report. It includes accounts of the work on the physiology of flight at high altitudes and of deep-sea diving; the design of clothing for airmen and for life in arctic and tropical climates; the human problems associated with submarines and surface ships; the design of aircraft, guns and armoured vehicles in relation to the abilities and needs of the men who use them; and the special problems, physiological and psychological, arising from the use of complicated panels of instruments, engine controls and similar devices inseparable from modern mechanized warfare and industry.

As the report says, the main factor limiting the efficiency of a machine or weapon may be the human being using it, so that machines and weapons should not be designed by physicists and engineers without the co-operation of the psychologist, the physiologist and the medical man. To industry the same considerations apply. Lighting, heating, ventilation, noise, dust, toxic products of the factory-all these, as well as the relations between the machine and the people who use them, need scientific study if the best economic, social and humane results are to be attained.

During the period covered by the report the Medical Research Council has unhappily lost by death or retiroment the services of men whose experience and creative ability were very valuable. The deaths of Sir Patrick Laidlaw and Sir Thomas Lewis, to whose influence and achievement the report pays tributes, were grievous blows. Although Sir Henry Dale retired after twenty-eight years of active service, he remained on the Council for four years longer, and his wide experience and outstanding ability are still happily available in consultation. Sir Edward Mellanby, secretary of the Medical Research Council, is fortunately still in office. $\mathrm{He}$ must be well satisfied with this record of the work to which he has devoted so much wise counsel and prolonged hard work.

G. LAPAgE

\section{COUNCIL FOR SCIENTIFIC AND INDUSTRIAL RESEARCH, AUSTRALIA}

\section{ANNUAL REPORT}

$T$ HE twentieth annual report of the Council for Scientific and Industrial Research, Common. wealth of Australia, covering the year ended June 30, 1946 (Canberra : Gov. Printer. 5s. 4d.), now available, refers to the decision to establish a Division of Textile Research as a result of the visits of Mr. B. $\mathbf{H}$. Wilsdon, Prof. J. B. Speakman, Dr. F. T. Peirce and Dr. A. C. Goodings mentioned in an earlier report; negotiations are in hand for the acquisition of a site for the headquarters laboratory at Geelong. Some work in the wool textile field will be undertaken by existing divisions.

The Building Materials Research Section and the Flax Research Laboratory came into existence dur. ing the year, and experimental work in nuclear physics and metallurgy was initiated in collaboration with the University of Melbourne. The Council has resumed its earlier practice of sending members of its scientific staff overseas to collect information on new developments and to acquire general experience in research and training in new techniques. A series of studentships is also to be offered each year to enable recent graduates of Australian universities to gain general research experience and training overseas in subjects related to the Council's programme of research, and then to return to Australia as members of the Council's staff. The Council's scientific liaison offices in London and Washington are now being maintained on a restricted basis to serve the peace-time needs of the Council.

With the end of the War, the Division of Plant Industry is devoting much more time to a study of pasture and weed problems, and the joint State and Council Weeds Co-ordination Committees are being revived. The North Australian Development Committee established by the Commonwealth Government and those of Queensland and Western Australia initiated a rapid examination, in the KatherineDarwin-coast area, of the vegetation in relation to geology, soils and climate, the distribution, grazing and quality of stock, etc., during the 1946 dry season. Another committee on which the Council is represented, with the Waite Agricultural Research Institute and the Departments of Agriculture of South Australia and Tasmania, has been established to supervise investigations of dieback or 'gummosis' of apricots. Pasture investigations have included the management of Phalaris - subterranean clover and of Wimmera rye grass-subterranean clover in sown pastures, and a large-scale grazing trial of natural pasture in co-operation with the New South Wales Department of Agriculture. Mineral deficiency, pasture establishment under cover crops, various studies of mixtures of lucerne and Paspalum sero- 